Article

\title{
Novel Azetidine-Containing TZT-1027 Analogues as Antitumor Agents
}

\author{
Qi Yan, Yujie Wang, Wei Zhang * and Yingxia Li * \\ School of Pharmacy, Fudan University, Shanghai 201203, China; yanq12@fudan.edu.cn (Q.Y.); \\ wyjbljy@163.com (Y.W.) \\ * Correspondence: zhangw416@fudan.edu.cn (W.Z.); liyx417@fudan.edu.cn (Y.L.); Tel: +86-21-5198-0120 (W.Z.); \\ +86-21-5198-0127 (Y.L.)
}

Academic Editor: Patrizia Diana

Received: 30 March 2016; Accepted: 22 April 2016; Published: 28 April 2016

\begin{abstract}
A conformational restriction strategy was used to design and synthesize nine TZT-1027 analogues. 3-Aryl-azetidine moiety was used to replace phenylethyl group of TZT-1027 at the C-terminus. These analogues exhibited moderate to excellent antiproliferative activities, and the most potent compound 1a showed IC $_{50}$ values of $2.2 \mathrm{nM}$ against A549 and $2.1 \mathrm{nM}$ against HCT116 cell lines, respectively. However, 1a could not achieve effective inhibition at all the dose levels in the A549 xenograft model (up to $5 \mathrm{mg} / \mathrm{kg}$, injection, once a day), which is only $16 \%-35 \%$ inhibition at the end of the experiment.
\end{abstract}

Keywords: TZT-1027; azetidine; conformation restriction; antiproliferative activity

\section{Introduction}

Dolastatin 10 and its natural analogues are highly-cytotoxic peptides isolated from the sea hare Dolabella auricularia from the India Ocean [1]. These compounds have been demonstrated to be effective against a broad spectrum of cancer cells [2]. The extraordinary cytotoxicity is caused by their ability to inhibit microtubule assembly and tubulin-dependent guanosine triphosphate (GTP) hydrolysis, which result in cell cycle arrest and apoptosis [3]. A large number of synthetic analogues of dolastatin 10 have been reported [4-6]. Some of them, such as TZT-1027, auristatin E, and auristatin PHE were advanced into clinical trials (Figure 1). However, significant side effects were observed in clinical trials at dose levels that were not sufficient to attain clinical efficacy $[7,8]$. MMAE, a monomethyl analog of Auristatin-E, was conjugated to monoclonal antibodies, leading to the discovery of the FDA approved ADC brentuximab vedotin (ADCETRIS) for the treatment of relapsed Hodgkin lymphoma and systemic anaplastic large cell lymphoma [9].

Conformational study of dolastatin 10 analogues bound to tubulin revealed a compact structure that folded around the central Val-Dil bond in its cis form, whereas the flexible C-terminus does not interact with any amino acid residue directly, indicating that its main role might be arranging the molecule's overall orientation [10,11]. Here we introduced azetidine moiety into C-terminus of TZT-1027 to explore the effect of conformational restriction on potency (Figure 2) [12]. Thus, nine conformational restricted analogues were synthesized and evaluated for inhibitory effects. 

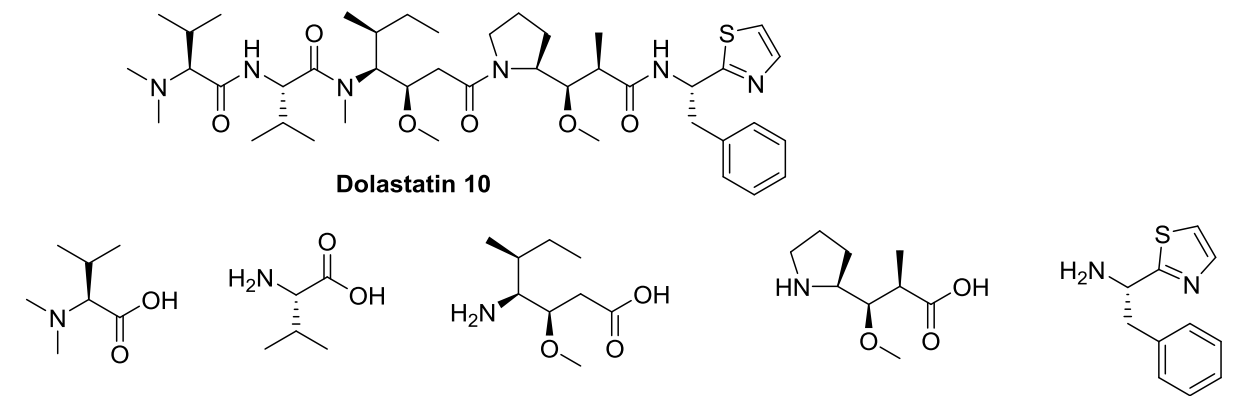

(S)-Dolavalin

(S)-Valine

$(3 R, 4 S, 5 S)$-Dolaisoleuine (Dov)<smiles>CCC(C)C(C(C)CC(=O)N1CCCC1C(OC)C(C)C(=O)NCCc1ccccc1)N(C)C(=O)[C@H](NC(=O)C(N(C)C)N(C)C)C(C)C</smiles>

TZT-1027<smiles>CCC(C)[C@H](C(CC(=O)N1CCCC1C(OC)C(C)C(=O)N[C@@H](Cc1ccccc1)C(=O)OC)OC)N(C)C(=O)[C@@H](NC(=O)C(C(C)C)N(C)C)C(C)C</smiles>

Auristatin-PHE<smiles>CCC(C)[C@H](C(CC(=O)N1CCCC1C(OC)[C@@H](C)C(=O)N[C@@H](C)C(O)c1ccccc1)OC)N(C)C(=O)[C@@H](NC(=O)C(C(C)C)N(C)C)C(C)C</smiles>

Auristatin-E<smiles>CCC(C)[C@H](CC(=O)N1CCCC1C(OC)[C@@H](C)C(=O)NC(C)[C@H](O)c1ccccc1)N(C)C(=O)[C@@H](NC(=O)C(NC)C(C)C)C(C)C</smiles>

MMAE

Figure 1. Structures of dolastatin 10 and its representative analogues.<smiles>CC[C@H](C)[C@H]([C@H](CC(=O)N1CCC[C@H]1[C@H](OC)[C@@H](C)C(=O)NCCc1ccccc1)OC)N(C)C(=O)[C@@H](NC(=O)[C@H](C(C)C)N(C)C)C(C)C</smiles>

TZT-1027

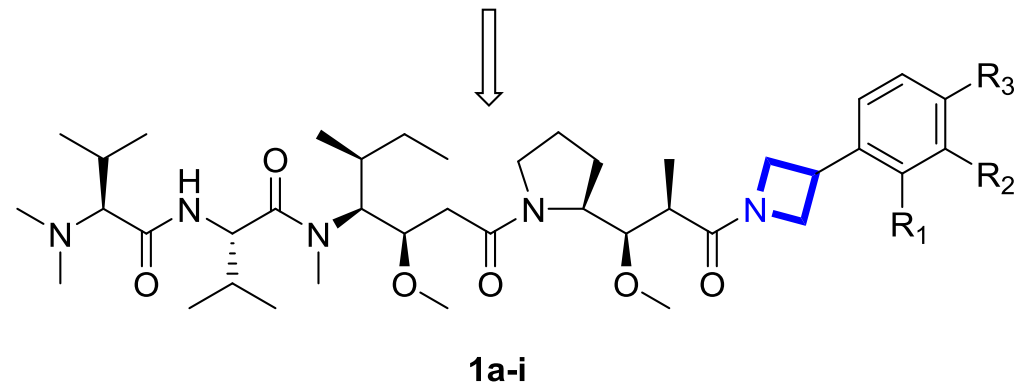

Figure 2. Designed target compounds.

\section{Results and Discussion}

\subsection{Chemistry}

The synthetic route is outlined in Scheme 1. 3-Aryl-azetidines 5a-i were prepared according to known procedure [13]. Removal of the Boc group with trifluoroacetic acid (TFA) yielded the TFA salts 6a-i, which were coupled with $N$-Boc- $(2 R, 3 R, 4 S)$-dolaproine (Dap) in the presence of HATU to give compounds $7 \mathbf{a}-\mathbf{i}$. Removal of the Boc group with TFA in $\mathbf{7 a - i}$ yielded the TFA salts $8 \mathbf{a}-\mathbf{i}$, which were coupled with Dov-Val-Dil. TFA (9) in the presence of HATU to provide the title compounds [5]. 

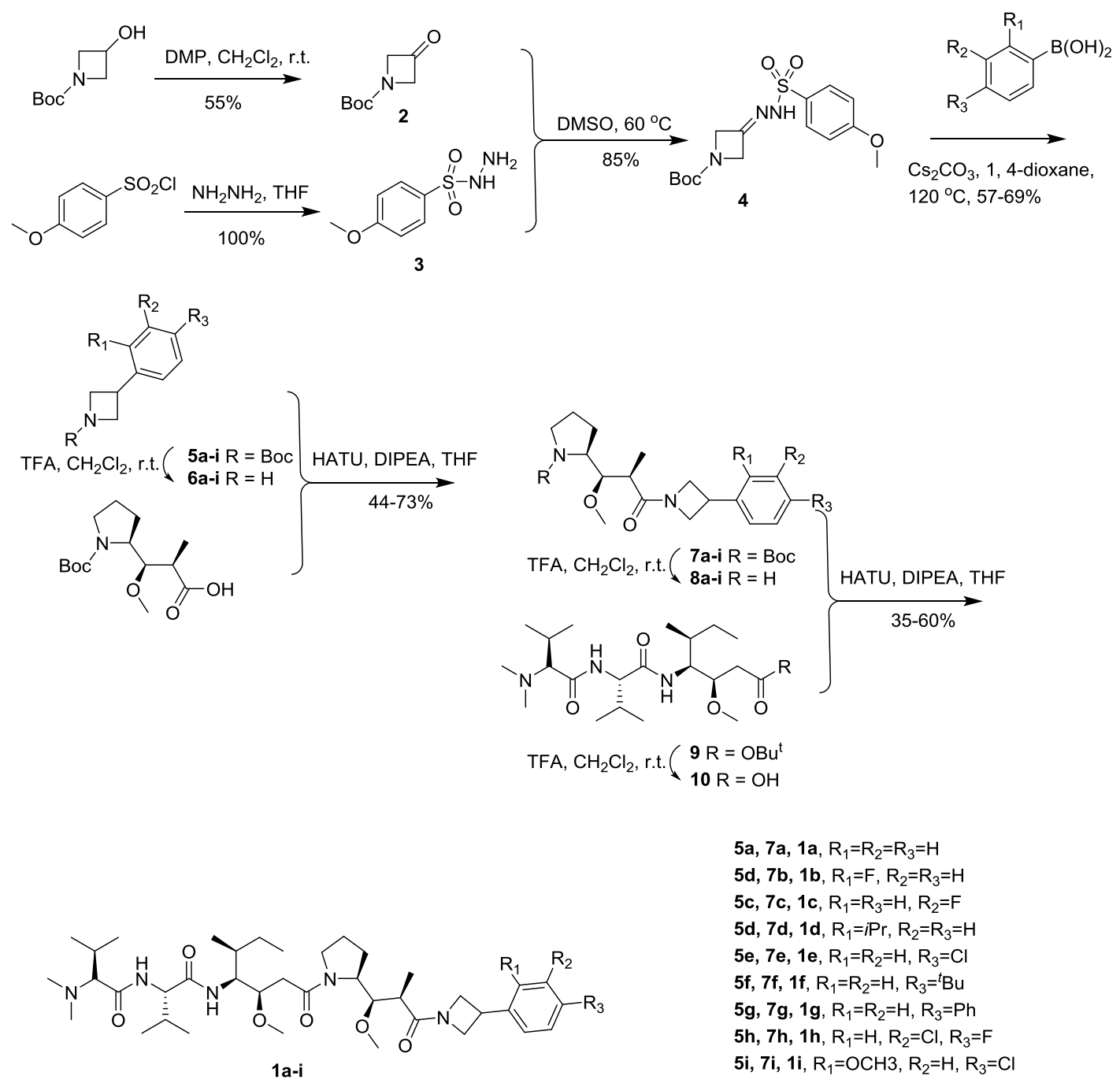

Scheme 1. Synthetic route of target compounds.

\subsection{In Vitro Antiproliferative Assay}

As shown in Table 1, these analogues demonstrated moderate to excellent antiproliferative activities. Among them, compound 1a was the most potent with $\mathrm{IC}_{50}$ values of $2.2 \mathrm{nM}$ against $\mathrm{A} 549$ cell lines and $2.1 \mathrm{nM}$ against HCT116 cell lines. Structure-activity relationship could not be well illustrated due to a limited set of compounds. Basically, different substitutions on the phenyl group such as ortho-fluor (1) $)$, meta-fluor (1c), para-chloro (1e), para-tert-butyl (1f), and para-phenyl (1) could not improve the antiproliferative activities. These compounds resulted in about 20-30-fold loss of potency against A549 cell lines. When a bulky isopropyl group was introduced to the ortho-position of phenyl group, inhibitory activity was reduced about 60 -folds (1d). All the target compounds showed weaker activity than TZT1027, indicating that conformational restriction at the C-terminus may not be beneficial to the activity. Membrane permeability can be a limiting factor for potency. The permeability data of synthesized compounds were not measured but we hypothesized that different substitutes of C-terminus could influence permeability, hence the antiproliferative activities. In addition, all the compounds showed better activity in HCT116 cell lines over A549 cell lines, demonstrating a cell selectivity. This is because HCT116 cells demonstrated a rapid proliferation rate than A549 cells and it is known that cytotoxic cancer drugs are believed to gain selectivity by targeting cells that proliferate rapidly. 
Table 1. $\mathrm{IC}_{50}$ values of compounds against A549 and HCT116 (MTT assay).

\begin{tabular}{ccc}
\hline Compounds & $\mathbf{A 5 4 9}(\mathbf{n M} \pm \mathbf{S D})^{\mathbf{a}}$ & $\mathbf{H C T 1 1 6} \mathbf{n M} \pm \mathbf{S D})^{\mathbf{a}}$ \\
\hline $\mathbf{1 a}$ & $2.2 \pm 4.8$ & $2.1 \pm 0.4$ \\
$\mathbf{1 b}$ & $47.0 \pm 9.9$ & $2.3 \pm 0.2$ \\
$\mathbf{1 c}$ & $35.0 \pm 0.6$ & $4.6 \pm 0.7$ \\
$\mathbf{1 d}$ & $130.1 \pm 48.3$ & $25.5 \pm 0.2$ \\
$\mathbf{1 e}$ & $19.5 \pm 1.7$ & $15.5 \pm 1.8$ \\
$\mathbf{1 f}$ & $56.0 \pm 3.3$ & $3.7 \pm 0.3$ \\
$\mathbf{1 g}$ & $41.5 \pm 13.3$ & $3.1 \pm 0.8$ \\
$\mathbf{1 h}$ & $39.3 \pm 2.4$ & $8.3 \pm 0.6$ \\
$\mathbf{1 i}$ & $8.7 \pm 3.7$ & $3.5 \pm 0.9$ \\
TZT-1027 & $0.2 \pm 0.06$ & $0.3 \pm 0.2$ \\
Docetaxel & $23.5 \pm 9.5$ & $0.3 \pm 0.1$ \\
\hline
\end{tabular}

a The data were means from at least three independent experiments.

\subsection{Inhibitory Activity of Compound 1a in A549 Xenograft Model}

Further in vivo antitumor activities of 1a was evaluated in A549 xenograft models in mice via tail vein intravenous injection for 22 days. It is reported that a dose of $4 \mathrm{mg} / \mathrm{kg}$ of TZT-1027 seemed to be toxic [14,15]. Considering of that, the maximum dose of $\mathbf{1 a}$ was chosen as $5 \mathrm{mg} / \mathrm{kg}$. After given $1 \mathrm{a}$ at $1 \mathrm{mg} / \mathrm{kg} /$ day, $2 \mathrm{mg} / \mathrm{kg} /$ day, and $5 \mathrm{mg} / \mathrm{kg} /$ day dosages, no overt toxicity and weight-loss were observed. However, compound 1a could not achieve effective inhibition at all the dose levels (Figure 3b). TZT-1027 ( $2 \mathrm{mg} / \mathrm{kg} /$ day) inhibited tumor growth by $61 \%$ over the 22 -day administration schedule, however 1a only inhibited tumor growth by $16 \%-35 \%$ at difference dose (Supplementary Materials, Tables S1-S3). No time- and dosage-dependent inhibition were observed. Higher dosage of 1a was not explored due to its poor solubility (Supplementary Materials, Table S4). Pharmacokinetic (PK) study was not conducted because in a mouse liver microsomes metabolic stability study, compound 1a demonstrated a $\mathrm{T}_{1 / 2}$ of less than 2 min (Supplementary Materials, Table S5). The synthesis of analogues suitable for formulation is of considerable interest and this work will be reported in due course.
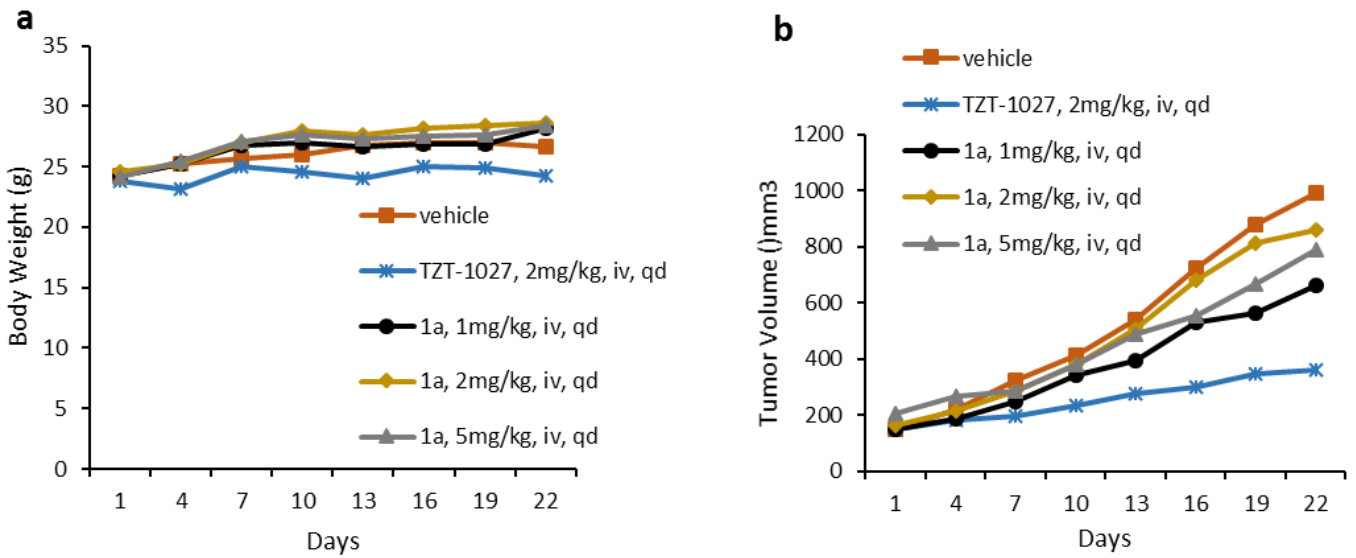

Figure 3. Antitumor activity of 1a in A549 xenograft mice at different dosages. (a) Body weight and (b) tumor volume were measured on the indicated days after treated with vehicle or 1a once a day.

\section{Experimental Section}

\subsection{Chemistry}

\subsubsection{General}

All starting materials, reagents, and solvents were commercially available. All reactions were monitored by thin-layer chromatography on silica gel plates (GF-254) and visualized with UV light. 
All the melting points were determined on a micromelting-point apparatus and thermometer was uncorrected. ${ }^{1} \mathrm{H}-\mathrm{NMR}$ spectra and ${ }^{13} \mathrm{C}-\mathrm{NMR}$ were recorded in acetone- $d_{6}$ or $\mathrm{CDCl}_{3}$ on a 400 or 600 Bruker NMR spectrometer with tetramethylsilane (TMS) as an internal reference. All chemical shifts are reported in parts per million ( $\mathrm{ppm})$. High-resolution exact mass measurements were performed using electrospray ionization (positive mode) on a quadrupole time-of-flight (QTOF) mass spectrometer (Maxis Q-TOF, Bruker Inc., Billerica, MA, USA).

\subsubsection{General Synthesis for 3-Aryl-Azetidines 5a-i}

To a solution of sulfonyl chloride (1.0 equiv) in $\operatorname{THF}(0.2 \mathrm{M})$ at $0{ }^{\circ} \mathrm{C}$ was added hydrazine hydrate (2.5 equiv) dropwise. The reaction mixture was stirred at $0{ }^{\circ} \mathrm{C}$ until complete conversion was observed by thin-layer chromatography. The mixture was diluted with EtOAc, washed with brine, dried over $\mathrm{Na}_{2} \mathrm{SO}_{4}$ and solvents removed in vacuo to give sulfonylhydrazides. To a solution of sulfonylhydrazones (1.0 equiv) in $\mathrm{MeOH}(0.5 \mathrm{M})$ was added ketone (1.0 equiv). The reaction mixture was stirred at room temperature until complete conversion was observed by TLC. Solvents were removed in vacuo to give sulfonylhydrazones. Sulfonylhydrazone $(0.5 \mathrm{mmol}, 1.0$ equiv), boronic acid $(0.75 \mathrm{mmol}, 1.5$ equiv), and cesium carbonate $(0.75 \mathrm{mmol}, 1.5$ equiv) were placed in an oven-dried tube in vacuo for $30 \mathrm{~min}$. The tube was backfilled with argon followed by the addition of dry degassed 1,4-dioxane $(2 \mathrm{~mL}, 0.25 \mathrm{M})$. This tube was sealed and heated to $110^{\circ} \mathrm{C}$ for $18 \mathrm{~h}$ before being cooled to room temperature, quenched with $\mathrm{NaHCO}_{3}(2 \mathrm{~mL}$ of a saturated aqueous solution), and extracted with $\mathrm{CH}_{2} \mathrm{Cl}_{2}(3 \times 5 \mathrm{~mL})$. The organic phase was dried over $\mathrm{MgSO}_{4}$, and solvents were removed in vacuo to give a residue, which was purified by flash column chromatography $(10 \%-30 \%$ EtOAc/hexane) to give the title compounds.

tert-Butyl 3-phenylazetidine-1-carboxylate (5a). Colorless oil; yield 57\%; ${ }^{1} \mathrm{H}-\mathrm{NMR}\left(400 \mathrm{MHz}, \mathrm{CDCl}_{3}\right)$ ס 7.39-7.29 (m, 4H), 7.27-7.23 (m, 1H), $4.33(\mathrm{t}, J=8.6 \mathrm{~Hz}, 2 \mathrm{H}), 3.98(\mathrm{t}, J=8.6 \mathrm{~Hz}, 2 \mathrm{H}), 3.73(\mathrm{tt}, J=8.6$, $6.0 \mathrm{~Hz}, 1 \mathrm{H}), 1.47(\mathrm{~s}, 3 \mathrm{H}) ;{ }^{13} \mathrm{C}-\mathrm{NMR}\left(150 \mathrm{MHz}, \mathrm{CDCl}_{3}\right) \delta$ 156.5, 142.3, 128.8, 127.0, 126.8, 79.6, 33.6, 28.5; HRMS (ESI) calcd for $\mathrm{C}_{14} \mathrm{H}_{19} \mathrm{NO}_{2} \mathrm{Na}$ : 256.1308, found: 256.1307.

tert-Butyl 3-(2-fluorophenyl)azetidine-1-carboxylate (5b). Colorless oil, yield 69\%; ${ }^{1} \mathrm{H}-\mathrm{NMR}(400 \mathrm{MHz}$, $\left.\mathrm{CDCl}_{3}\right) \delta 7.31(\mathrm{~d}, J=7.8 \mathrm{~Hz}, 1 \mathrm{H}), 7.08(\mathrm{~d}, J=7.7 \mathrm{~Hz}, 1 \mathrm{H}), 7.02(\mathrm{~d}, J=9.9 \mathrm{~Hz}, 1 \mathrm{H}), 6.96(\mathrm{t}, J=8.3 \mathrm{~Hz}, 1 \mathrm{H})$, $4.33(\mathrm{t}, J=8.7 \mathrm{~Hz}, 2 \mathrm{H}), 3.99-3.92(\mathrm{~m}, 2 \mathrm{H}), 3.72-3.70(\mathrm{~m}, 1 \mathrm{H}), 1.47(\mathrm{~s}, 9 \mathrm{H}) ;{ }^{13} \mathrm{C}-\mathrm{NMR}\left(150 \mathrm{MHz}, \mathrm{CDCl}_{3}\right) \delta$ $161.7,160.1,156.5,128.8,128.7,128.6,128.6,128.0,127.9,124.4,115.6,115.4,79.6,29.8,28.5,27.6,27.5$; HRMS (ESI) calcd for $\mathrm{C}_{14} \mathrm{H}_{18} \mathrm{NO}_{2} \mathrm{FNa}$ : 274.1214, found: 256.1215 .

tert-Butyl 3-(3-fluorophenyl)azetidine-1-carboxylate (5c). Colorless oil, yield 62\%; ${ }^{1} \mathrm{H}-\mathrm{NMR}(400 \mathrm{MHz}$, $\left.\mathrm{CDCl}_{3}\right) \delta 7.31(\mathrm{td}, J=7.9,6.1 \mathrm{~Hz}, 1 \mathrm{H}), 7.08(\mathrm{~d}, J=7.7 \mathrm{~Hz}, 1 \mathrm{H}), 7.03(\mathrm{dt}, J=10.0,2.1 \mathrm{~Hz}, 1 \mathrm{H}), 6.96$ $(\mathrm{td}, J=8.6,2.9 \mathrm{~Hz}, 1 \mathrm{H}), 4.33(\mathrm{t}, J=8.7 \mathrm{~Hz}, 2 \mathrm{H}), 3.96(\mathrm{dd}, J=8.6,5.9 \mathrm{~Hz}, 2 \mathrm{H}), 3.77-3.68(\mathrm{~m}, 1 \mathrm{H}), 1.42$ (s, 9H); ${ }^{13} \mathrm{C}-\mathrm{NMR}\left(150 \mathrm{MHz}, \mathrm{CDCl}_{3}\right) \delta 163.2,161.6,155.7,144.1,144.1,129.7,129.6,129.5,121.7,121.7$, 113.3, 113.2, 113.1, 79.1, 76.5, 76.3, 76.1, 32.6, 27.7, 27.6; HRMS (ESI) calcd for $\mathrm{C}_{14} \mathrm{H}_{18} \mathrm{NO}_{2} \mathrm{FNa}$ : 274.1214, found: 256.1215 .

tert-Butyl 3-(2-isopropylphenyl)azetidine-1-carboxylate (5d). Colorless oil, yield 57\%; ${ }^{1} \mathrm{H}-\mathrm{NMR}$ $\left(400 \mathrm{MHz}, \mathrm{CDCl}_{3}\right)$ 8 7.45-7.39 (m, 1H), 7.31-7.20 (m, 3H), $4.31(\mathrm{t}, J=8.0 \mathrm{~Hz}, 2 \mathrm{H}), 4.13-4.05(\mathrm{~m}, 1 \mathrm{H})$, $4.03(\mathrm{~m}, 2 \mathrm{H}), 1.46(\mathrm{~s}, 10 \mathrm{H}), 1.21(\mathrm{~s}, 3 \mathrm{H}), 1.19(\mathrm{~s}, 3 \mathrm{H}) ;{ }^{13} \mathrm{C}-\mathrm{NMR}\left(150 \mathrm{MHz}, \mathrm{CDCl}_{3}\right) \delta 156.6,146.6,138.3$, 127.2, 126.3, 125.7, 125.4, 79.6, 29.8, 29.1, 28.5, 23.9; HRMS (ESI) calcd for $\mathrm{C}_{17} \mathrm{H}_{25} \mathrm{NO}_{2} \mathrm{Na}$ : 298.1778, found: 258.1777 .

tert-Butyl 3-(4-chlorophenyl)azetidine-1-carboxylate (5e). Colorless oil, yield 50\%; ${ }^{1} \mathrm{H}-\mathrm{NMR}(400 \mathrm{MHz}$, $\left.\mathrm{CDCl}_{3}\right) \delta 7.30(\mathrm{~d}, J=8.1 \mathrm{~Hz}, 2 \mathrm{H}), 7.22(\mathrm{~d}, J=8.1 \mathrm{~Hz}, 2 \mathrm{H}), 4.31(\mathrm{t}, J=8.7 \mathrm{~Hz}, 2 \mathrm{H}), 3.91(\mathrm{dd}, J=8.6$, $5.8 \mathrm{~Hz}, 2 \mathrm{H}), 3.72-3.63(\mathrm{~m}, 1 \mathrm{H}), 1.46(\mathrm{~s}, 9 \mathrm{H}) ;{ }^{13} \mathrm{C}-\mathrm{NMR}\left(150 \mathrm{MHz}, \mathrm{CDCl}_{3}\right) \delta 161.0,159.3,155.7,127.9$, 127.8, 127.2, 127.2, 123.7, 123.6, 114.8, 114.7, 78.9, 27.7; HRMS (ESI) calcd for $\mathrm{C}_{14} \mathrm{H}_{18} \mathrm{ClNO}_{2} \mathrm{Na}$ : 290.0918, found: 290.0916 . 
tert-Butyl 3-(4-(tert-butyl)phenyl)azetidine-1-carboxylate (5f). Colorless oil, yield 53\%; ${ }^{1} \mathrm{H}-\mathrm{NMR}$ $\left(400 \mathrm{MHz}, \mathrm{CDCl}_{3}\right) \delta 7.38(\mathrm{~d}, J=8.3 \mathrm{~Hz}, 2 \mathrm{H}), 7.25(\mathrm{~d}, J=8.1 \mathrm{~Hz}, 2 \mathrm{H}), 4.31(\mathrm{t}, J=8.6 \mathrm{~Hz}, 2 \mathrm{H}), 4.02-3.93$ (m, 2H), 3.71-3.69 (m, 1H), 1.47 (s, 9H), 1.32 (s, 9H); ${ }^{13} \mathrm{C}-\mathrm{NMR}\left(150 \mathrm{MHz}, \mathrm{CDCl}_{3}\right) \delta 155.8,149.2,138.5$, 125.8, 124.9, 78.8, 33.8, 32.4, 30.7, 27.8; HRMS (ESI) calcd for $\mathrm{C}_{18} \mathrm{H}_{27} \mathrm{NO}_{2} \mathrm{Na}$ : 312.1934, found: 312.1936.

tert-Butyl 3-([1,1'-biphenyl]-4-yl)azetidine-1-carboxylate (5g). Colorless oil, yield $66 \% ;{ }^{1} \mathrm{H}-\mathrm{NMR}$ $\left(400 \mathrm{MHz}, \mathrm{CDCl}_{3}\right) \delta 7.58(\mathrm{~d}, J=7.8 \mathrm{~Hz}, 4 \mathrm{H}), 7.44(\mathrm{t}, J=7.5 \mathrm{~Hz}, 2 \mathrm{H}), 7.39-7.32(\mathrm{~m}, 3 \mathrm{H}), 4.35(\mathrm{t}, J=8.6 \mathrm{~Hz}$, 2H), 4.08-3.97 (m, 2H), 3.78-3.75 (m, 1H), $1.48(\mathrm{~s}, 9 \mathrm{H}) ;{ }^{13} \mathrm{C}-\mathrm{NMR}\left(150 \mathrm{MHz}, \mathrm{CDCl}_{3}\right) \delta$ 155.8, 140.6, 140.0, 139.3, 128.1, 128.1, 126.8, 126.6, 126.5, 126.4, 78.9, 27.8; HRMS (ESI) calcd for $\mathrm{C}_{20} \mathrm{H}_{23} \mathrm{NO}_{2} \mathrm{Na}$ : 332.1621, found: 332.1623 .

tert-Butyl 3-(3-chloro-4-fluorophenyl)azetidine-1-carboxylate (5h). Colorless oil, yield 55\%; ${ }^{1} \mathrm{H}-\mathrm{NMR}$ $\left(400 \mathrm{MHz}, \mathrm{CDCl}_{3}\right)$ 8 7.39-7.34 (m, 1H), 7.21-7.15 (m, 1H), $7.12(\mathrm{t}, J=7.8 \mathrm{~Hz}, 1 \mathrm{H}), 4.33(\mathrm{t}, J=8.7 \mathrm{~Hz}, 2 \mathrm{H})$, 3.95-3.87 (m, 2H), 3.73-3.63 (m, 1H), $1.47(\mathrm{~s}, 9 \mathrm{H}) ;{ }^{13} \mathrm{C}-\mathrm{NMR}\left(150 \mathrm{MHz}, \mathrm{CDCl}_{3}\right)$ \& 156.3, 139.3, 129.0, 126.5, $126.45,121.2,117.2,116.8,116.7,114.7,79.8,56.5,32.7,28.4$; HRMS (ESI) calcd for $\mathrm{C}_{14} \mathrm{H}_{17} \mathrm{ClFNO}_{2} \mathrm{Na}$ : 308.0830, found: 308.0829 .

tert-Butyl 3-(4-chloro-2-methoxyphenyl)azetidine-1-carboxylate (5i). Colorless oil, yield $62 \% ;{ }^{1} \mathrm{H}-\mathrm{NMR}$ $\left(400 \mathrm{MHz}, \mathrm{CDCl}_{3}\right) \delta 6.94(\mathrm{dd}, J=8.1,1.8 \mathrm{~Hz}, 1 \mathrm{H}), 6.83(\mathrm{~d}, J=1.7 \mathrm{~Hz}, 1 \mathrm{H}), 4.25(\mathrm{t}, J=8.4 \mathrm{~Hz}, 2 \mathrm{H}), 4.04-3.86$ (m, 3H), 3.80 (s, 3H), 1.45 (s, 9H); ${ }^{13} \mathrm{C}-\mathrm{NMR}\left(150 \mathrm{MHz}, \mathrm{CDCl}_{3}\right) \delta$ 157.2, 155.9, 132.6, 127.6, 127.1, 119.8, 110.4, 78.7, 54.9, 27.9, 27.8; HRMS (ESI) calcd for $\mathrm{C}_{15} \mathrm{H}_{20} \mathrm{ClNO}_{3} \mathrm{Na}$ : 320.1024, found: 320.1024.

\subsubsection{General Synthesis for $7 \mathbf{a}-\mathbf{i}$}

Compounds 5a-i (1 equiv.) were dissolved in $2 \mathrm{~mL} \mathrm{CH}_{2} \mathrm{Cl}_{2} / \mathrm{TFA}(1: 1, v / v)$ at $0{ }^{\circ} \mathrm{C}$, and the mixture was stirred for $1 \mathrm{~h}$ at room temperature. The reaction was then concentrated in vacuum, followed by azeotroping with dichloromethane three times to obtain the trifluoroacetate salts. To a stirring solution of the Dap in dry dichloromethane at $0{ }^{\circ} \mathrm{C}$ were sequentially added HATU (1.5 equiv.). After $10 \mathrm{~min}$, the previously prepared trifluoroacetate salts dissolved in dichloromethane was added to reaction mixture followed by the addition of DIPEA (3 equiv.). After stirring for $12 \mathrm{~h}$ at room temperature, the reaction mixture was diluted with EtOAc $/ \mathrm{CH}_{2} \mathrm{Cl}_{2}$, washed with $1 \mathrm{M} \mathrm{HCl}$, saturated $\mathrm{NaHCO}_{3}$ solution, water and brine, dried, filtered and concentrated in vacuo. Purification by silica gel column chromatography (EtOAc/Petroleum ether, 1/1) afforded compounds $7 \mathbf{a}-\mathbf{i}$.

tert-Butyl (S)-2-((1R,2R)-1-methoxy-2-methyl-3-oxo-3-(3-phenylazetidin-1-yl)propyl)pyrrolidine-1carboxylate (7a). Colorless oil, yield 57\%; ${ }^{1} \mathrm{H}-\mathrm{NMR}\left(400 \mathrm{MHz}, \mathrm{CDCl}_{3}\right) \delta 7.39-7.34(\mathrm{~m}, 2 \mathrm{H}), 7.30-7.29$ $(\mathrm{m}, 3 \mathrm{H}), 4.58-4.51(\mathrm{~m}, 1 \mathrm{H}), 4.45-4.34(\mathrm{~m}, 1 \mathrm{H}), 4.20-4.01(\mathrm{~m}, 2 \mathrm{H}), 3.91-3.87(\mathrm{~m}, 1 \mathrm{H}), 3.78-3.76$ $(\mathrm{m}, 2 \mathrm{H}), 3.46(\mathrm{~s}, 3 \mathrm{H}), 3.29-3.23(\mathrm{~m}, 1 \mathrm{H}), 2.41-2.37(\mathrm{~m}, 1 \mathrm{H}), 2.01-1.93(\mathrm{~m}, 2 \mathrm{H}), 1.85-1.72(\mathrm{~m}, 1 \mathrm{H})$, $4.52(\mathrm{~d}, J=10.6 \mathrm{~Hz}, 3 \mathrm{H}), 1.25(\mathrm{~s}, 9 \mathrm{H}) ;{ }^{13} \mathrm{C}-\mathrm{NMR}\left(150 \mathrm{MHz}, \mathrm{CDCl}_{3}\right) \delta 148.9,139.4,135.0,128.5,128.1$, 127.7, 124.8, 124.5, 120.0, 53.5, 50.9, 41.9, 41.5, 28.1, 25.8, 19.5, 18.7, 12.1, 10.8. HRMS (ESI) calcd for $\mathrm{C}_{23} \mathrm{H}_{35} \mathrm{~N}_{2} \mathrm{O}_{4}$ : 403.2591, found: 403.2597; $[\alpha]_{\mathrm{D}}^{25}-35.000\left(\mathrm{CHCl}_{3}, c=0.50\right)$.

tert-Butyl (S)-2-((1R,2R)-3-(3-(2-fluorophenyl)azetidin-1-yl)-1-methoxy-2-methyl-3-oxopropyl)pyrro lidine-1-carboxylate (7b). Colorless oil, yield $60 \% ;{ }^{1} \mathrm{H}-\mathrm{NMR}\left(400 \mathrm{MHz}, \mathrm{CDCl}_{3}\right) \delta 7.27-7.10(\mathrm{~m}, 1 \mathrm{H})$, 6.96-6.94 (m, 1H), $6.83(\mathrm{~d}, J=1.7 \mathrm{~Hz}, 1 \mathrm{H}), 4.50-4.43(\mathrm{~m}, 1 \mathrm{H}), 4.35-4.31(\mathrm{~m}, 1 \mathrm{H}), 4.27-4.24(\mathrm{~m}, 1 \mathrm{H})$, 4.19-4.08 (m, 2H), 3.97-3.82 (m, 3H), $3.81(\mathrm{~s}, 3 \mathrm{H}), 3.78-3.74(\mathrm{~m}, 1 \mathrm{H}), 3.26-3.22(\mathrm{~m}, 1 \mathrm{H}), 1.95(\mathrm{~s}, 3 \mathrm{H})$, $1.92-1.68(\mathrm{~m}, 4 \mathrm{H}), 1.52(\mathrm{~s}, 3 \mathrm{H}), 1.44(\mathrm{~d}, J=7.8 \mathrm{~Hz}, 3 \mathrm{H}) ;{ }^{13} \mathrm{C}-\mathrm{NMR}\left(150 \mathrm{MHz}, \mathrm{CDCl}_{3}\right) \delta 174.4,154.6$, 129.0, 128.1, 128.0, 124.5, 115.8, 84.2, 84.1, 82.1, 79.9, 79.1, 61.2, 60.8, 59.5, 59.3, 58.9, 56.4, 53.5, 53.3, 47.0, 46.7, 39.2, 38.4, 28.7, 28.6, 27.8, 27.4, 26.2, 26.1, 25.7, 24.7, 24.6, 24.3, 14.7, 14.6, 13.8; HRMS (ESI) calcd for $\mathrm{C}_{23} \mathrm{H}_{33} \mathrm{~N}_{2} \mathrm{O}_{4} \mathrm{FNa}$ : 443.2317, found: 443.2318; $[\alpha]_{\mathrm{D}}^{25}-42.000\left(\mathrm{CHCl}_{3}, c=0.50\right)$.

tert-Butyl (S)-2-((1R,2R)-3-(3-(3-fluorophenyl)azetidin-1-yl)-1-methoxy-2-methyl-3-oxopropyl)pyrro lidine-1-carboxylate (7c). Colorless oil, yield 55\%; ${ }^{1} \mathrm{H}-\mathrm{NMR}\left(400 \mathrm{MHz}, \mathrm{CDCl}_{3}\right) 7.31-7.27(\mathrm{~m}, 1 \mathrm{H}), 7.07$ $(\mathrm{d}, J=7.4 \mathrm{~Hz}, 1 \mathrm{H}), 7.02-6.97(\mathrm{~m}, 2 \mathrm{H}), 4.64-4.49(\mathrm{~m}, 2 \mathrm{H}), 4.40-4.35(\mathrm{~m}, 1 \mathrm{H}), 4.26-4.03(\mathrm{~m}, 1 \mathrm{H}), 4.02-3.96$ 
(m, 1H), 3.94-3.84 (m, 1H), 3.83-3.74 (m, 1H), 3.64-3.50 (m, 1H), $3.45(\mathrm{~s}, 3 \mathrm{H}), 3.30-3.21(\mathrm{~m}, 2 \mathrm{H}), 1.99-1.91$ $(\mathrm{m}, 3 \mathrm{H}), 1.89-1.72(\mathrm{~m}, 2 \mathrm{H}),[1.52(\mathrm{~s}), 1.47(\mathrm{~s}), 1.44(\mathrm{~s})$, total $9 \mathrm{H}], 1.24(\mathrm{~d}, J=6.9 \mathrm{~Hz}, 3 \mathrm{H}),{ }^{13} \mathrm{C}-\mathrm{NMR}$ $\left(150 \mathrm{MHz}, \mathrm{CDCl}_{3}\right) \delta$ 163.9, 163.9, 162.3, 162.2, 154.5, 130.4, 122.3, 114.1, 113.6, 113.5, 84.3, 84.1, 82.6, 82.3, 79.8, 79.1, 61.0, 60.7, 60.4, 58.7, 57.4, 57.4, 54.8, 54.6, 46.9, 46.8, 38.5, 32.8, 28.6, 26.2, 24.1, 14.5, 14.2; HRMS (ESI) calcd for $\mathrm{C}_{23} \mathrm{H}_{33} \mathrm{~N}_{2} \mathrm{O}_{4} \mathrm{FNa}$ 443.2317, found: 443.2321; $[\alpha]_{\mathrm{D}}^{25}-66.200\left(\mathrm{CHCl}_{3}, c=0.50\right)$.

tert-Butyl (S)-2-((1R,2R)-3-(3-(2-isopropylphenyl)azetidin-1-yl)-1-methoxy-2-methyl-3-oxopropyl)pyrro lidine-1-carboxylate (7d). Colorless oil, yield $65 \% ;{ }^{1} \mathrm{H}-\mathrm{NMR}\left(400 \mathrm{MHz}, \mathrm{CDCl}_{3}\right) 7.37-7.35(\mathrm{~m}, 1 \mathrm{H})$, 7.28-7.24 (m, 3H), 4.56-4.51 (m, 1H), 4.43-4.34 (m, 1H), 4.22-4.07 (m, 3H), 3.88-3.77 (m, 3H), 3.57-3.55 $(\mathrm{m}, 1 \mathrm{H}),[3.45(\mathrm{~s})$ and $3.44(\mathrm{~s})$, total $3 \mathrm{H}], 3.26-3.23(\mathrm{~m}, 1 \mathrm{H}), 3.01-2.93(\mathrm{~m}, 1 \mathrm{H}), 2.50-2.39(\mathrm{~m}, 1 \mathrm{H})$, 1.95-1.72 (m, 6H), [1.51 (s), $1.47(\mathrm{~s})$ and $1.43(\mathrm{~s})$, total 9H], 1.25-1.19 $(\mathrm{m}, 9 \mathrm{H}) ;{ }^{13} \mathrm{C}-\mathrm{NMR}(150 \mathrm{MHz}$, $\left.\mathrm{CDCl}_{3}\right) \delta$ 173.6, 173.3, 153.9, 145.9, 137.2, 126.8, 125.6, 124.8, 124.6, 124.5, 83.6, 83.4, 81.9, 81.8, 79.2, 78.4, $60.5,58.2,58.1,56.3,56.2,53.6,53.4,46.3,46.0,38.5,37.9,29.0,28.5,28.4,28.0,27.9,25.5,23.5,23.2,23.1$, 13.9; HRMS (ESI) calcd for $\mathrm{C}_{26} \mathrm{H}_{41} \mathrm{~N}_{2} \mathrm{O}_{4}: 445.3061$, found: 445.3065; $[\alpha]_{\mathrm{D}}^{25}-46.200\left(\mathrm{CHCl}_{3}, c=0.50\right)$.

tert-Butyl (S)-2-((1R,2R)-3-(3-(4-chlorophenyl)azetidin-1-yl)-1-methoxy-2-methyl-3-oxopropyl)pyrro lidine-1-carboxylate (7e). Colorless oil, yield $45 \% ;{ }^{1} \mathrm{H}-\mathrm{NMR}\left(400 \mathrm{MHz}, \mathrm{CDCl}_{3}\right) 7.33-7.32(\mathrm{~m}, 2 \mathrm{H})$, 7.24-7.22 (m, 2H), 4.58-4.36 (m, 2H), 4.17-3.75 (m, 5H), 3.60-3.55 (m, 1H), [3.45 (s) and $3.44(\mathrm{~s})$, total $3 \mathrm{H}$ ], 3.30-3.24 (m, 1H), 2.47-2.40 (m, 1H), 1.95-1.74 (m, 6H), [1.52 (s), $1.47(\mathrm{~s})$ and $1.44(\mathrm{~s})$, total 9H], $1.23(\mathrm{~d}, J=7.4 \mathrm{~Hz}, 3 \mathrm{H}) ;{ }^{13} \mathrm{C}-\mathrm{NMR}\left(150 \mathrm{MHz}, \mathrm{CDCl}_{3}\right) \delta 173.9,173.6,173.4,153.8,139.6,139.4,132.4$, $128.3,127.3,83.6,83.4,81.9,81.7,79.2,78.4,60.4,60.1,58.1,56.9,54.2,54.1,46.3,46.0,37.9,37.8,31.9$, 29.0, 28.0, 25.6, 23.5; HRMS (ESI) calcd for $\mathrm{C}_{23} \mathrm{H}_{33} \mathrm{ClN}_{2} \mathrm{O}_{4} \mathrm{Na}$ : 459.2021, found: 459.2024; $[\alpha]_{\mathrm{D}}^{25}-46.600$ $\left(\mathrm{CHCl}_{3}, c=0.50\right)$.

tert-Butyl (S)-2-((1R,2R)-3-(3-(4-(tert-butyl)phenyl)azetidin-1-yl)-1-methoxy-2-methyl-3-oxopropyl)py rrolidine-1-carboxylate (7f). Colorless oil, yield 73\%; ${ }^{1} \mathrm{H}-\mathrm{NMR}\left(400 \mathrm{MHz}, \mathrm{CDCl}_{3}\right) \delta 7.39(\mathrm{~d}, J=6.8 \mathrm{~Hz}$, $2 \mathrm{H}), 7.24(\mathrm{~d}, J=8.1 \mathrm{~Hz}, 2 \mathrm{H}), 4.56-4.51(\mathrm{~m}, 1 \mathrm{H}), 4.43-4.32(\mathrm{~m}, 1 \mathrm{H}), 4.17-4.01(\mathrm{~m}, 3 \mathrm{H}), 3.89-3.74(\mathrm{~m}, 3 \mathrm{H})$, $3.60-3.55(\mathrm{~m}, 1 \mathrm{H}),[3.46(\mathrm{~s})$ and $3.45(\mathrm{~s})$, total $3 \mathrm{H}], 3.30-3.25(\mathrm{~m}, 1 \mathrm{H}), 2.47-2.39(\mathrm{~m}, 2 \mathrm{H}), 1.98-1.74(\mathrm{~m}, 6 \mathrm{H})$, [1.52 (s), $1.47(\mathrm{~s})$ and $1.45(\mathrm{~s})$, total 9H], [1.32 $(\mathrm{s})$ and $1.31(\mathrm{~s})$, total $9 \mathrm{H}], 1.24(\mathrm{~d}, J=7.4 \mathrm{~Hz}, 3 \mathrm{H}) ;{ }^{13} \mathrm{C}-\mathrm{NMR}$ $\left(150 \mathrm{MHz}, \mathrm{CDCl}_{3}\right) \delta$ 173.9, 173.7, 173.6, 173.3, 153.8, 149.6, 149.5, 138.1, 137.9, 125.7, 125.1, 83.6, 83.4, 81.9, 81.8, 79.2, 78.4, 60.50, 58.1, 57.1, 54.4, 54.2, 46.0, 37.8, 33.8, 32.1, 31.9, 30.6, 28.0, 27.9, 25.6, 25.5, 23.6, 13.9; HRMS (ESI) calcd for $\mathrm{C}_{27} \mathrm{H}_{43} \mathrm{~N}_{2} \mathrm{O}_{4}: 4059.3217$, found: 459.3220 ; $[\alpha]_{\mathrm{D}}^{25}-73.200\left(\mathrm{CHCl}_{3}, c=1\right)$.

tert-Butyl (S)-2-((1R,2R)-3-(3-([1,1'-biphenyl]-4-yl)azetidin-1-yl)-1-methoxy-2-methyl-3-oxopropyl)pyrr olidine-1-carboxylate (7g). Colorless oil, yield $45 \% ;{ }^{1} \mathrm{H}-\mathrm{NMR}\left(400 \mathrm{MHz}, \mathrm{CDCl}_{3}\right) \delta 7.59(\mathrm{~d}, J=7.1 \mathrm{~Hz}$, $4 \mathrm{H}), 7.45(\mathrm{t}, J=7.6 \mathrm{~Hz}, 3 \mathrm{H}), 7.46-7.33(\mathrm{~m}, 3 \mathrm{H}), 4.60-4.53(\mathrm{~m}, 1 \mathrm{H}), 4.47-4.36(\mathrm{~m}, 1 \mathrm{H}), 4.25-4.04(\mathrm{~m}, 3 \mathrm{H})$, 3.89-3.79 (m, 3H), 3.60-3.55 (m, 1H), 3.46 (s, 3H), 3.28-3.25 (m, 1H), 2.53-2.41 (m, 1H), 1.97-1.75 (m, 5H), [1.52 (s), $1.48(\mathrm{~s})$ and $1.44(\mathrm{~s})$, total 9H], $1.25(\mathrm{~d}, J=7.4 \mathrm{~Hz}, 3 \mathrm{H}) ;{ }^{13} \mathrm{C}-\mathrm{NMR}\left(150 \mathrm{MHz}, \mathrm{CDCl}_{3}\right) \delta 173.6$, 173.4, 153.8, 139.9, 139.6, 128.2, 126.9, 126.7, 126.3, 83.6, 83.4, 81.9, 81.8, 79.2, 78.5, 60.5, 58.1, 57.1, 57.0, 54.3, 46.0, 37.8, 32.2, 32.1, 28.0, 27.9, 25.6, 23.5, 14.0. HRMS (ESI) calcd for $\mathrm{C}_{29} \mathrm{H}_{38} \mathrm{~N}_{2} \mathrm{O}_{4}$ : 479.2904, found: 4479.2910; $[\alpha]_{\mathrm{D}}^{25}-36.500\left(\mathrm{CHCl}_{3}, c=0.50\right)$.

tert-Butyl (S)-2-((1R,2R)-3-(3-(3-chloro-4-fluorophenyl)azetidin-1-yl)-1-methoxy-2-methyl-3-oxopropyl) pyrrolidine-1-carboxylate (7h). Colorless oil, yield 63\%; ${ }^{1} \mathrm{H}-\mathrm{NMR}\left(400 \mathrm{MHz}\right.$, acetone- $\left.d_{6}\right) \delta 8.58-7.54$ $(\mathrm{m}, 1 \mathrm{H}), 7.39-7.34(\mathrm{~m}, 2 \mathrm{H}), 4.57-4.45(\mathrm{~m}, 1 \mathrm{H}), 4.24-4.02(\mathrm{~m}, 4 \mathrm{H}), 3.88-3.59(\mathrm{~m}, 5 \mathrm{H}), 3.31(\mathrm{~s}, 3 \mathrm{H}), 3.15-3.09$ $(\mathrm{m}, 1 \mathrm{H}), 1.82-1.64(\mathrm{~m}, 6 \mathrm{H}), 1.39(\mathrm{~s}, 9 \mathrm{H}), 0.06(\mathrm{~d}, J=7.4 \mathrm{~Hz}, 3 \mathrm{H}) ;{ }^{13} \mathrm{C}-\mathrm{NMR}\left(150 \mathrm{MHz}\right.$, acetone- $\left.d_{6}\right) \delta$ 173.1, 172.9, 156.7, 155.1, 153.1, 140.1, 139.7, 139.7, 129.4, 128.9, 128.7, 127.4, 127.3, 127.2, 119.4, 119.3, 119.2, $116.9,116.8,116.7,83.7,83.6,81.8,81.7,78.4,78.0,60.3,60.1,58.6,58.2,56.8,56.4,54.2,46.4,46.2,31.3$, 28.0, 25.4, 24.9, 23.9, 23.4, 14.0; HRMS (ESI) calcd for $\mathrm{C}_{23} \mathrm{H}_{32} \mathrm{ClFN}_{2} \mathrm{O}_{4} \mathrm{Na}$ : 477.1927, found: 477.1927; $[\alpha]_{\mathrm{D}}^{25}-35.000\left(\mathrm{CHCl}_{3}, c=0.50\right)$.

tert-Butyl (S)-2-((1R,2R)-3-(3-(4-chloro-2-methoxyphenyl)azetidin-1-yl)-1-methoxy-2-methyl-3-oxoprop yl)pyrrolidine-1-carboxylate (7i). Colorless oil, yield $44 \% ;{ }^{1} \mathrm{H}-\mathrm{NMR}\left(400 \mathrm{MHz}, \mathrm{CDCl}_{3}\right) \delta 7.12-7.069$ (m, 1H), 6.95-6.92 (m, 1H), 6.85-6.84 (m, 1H), 4.48-4.43 (m, 1H), 4.33-4.05 (m, 3H), 3.96-3.81 (m, 2H), 
$3.80(\mathrm{~s}, 3 \mathrm{H}), 3.77-3.73(\mathrm{~m}, 1 \mathrm{H}), 3.56-3.54(\mathrm{~m}, 1 \mathrm{H})$, [3.44 $(\mathrm{s})$ and $3.43(\mathrm{~s})$, total $3 \mathrm{H}], 1.95-1.51(\mathrm{~m}, 5 \mathrm{H})$, [1.50 (s), $1.46(\mathrm{~s})$ and $1.42(\mathrm{~s})$, total $9 \mathrm{H}],[1.22(\mathrm{~d}, J=6.9 \mathrm{~Hz})$ and $1.18(\mathrm{~d}, J=6.9 \mathrm{~Hz})$, total $3 \mathrm{H}] ;{ }^{13} \mathrm{C}-\mathrm{NMR}$ $\left(150 \mathrm{MHz}, \mathrm{CDCl}_{3}\right) \delta 173.6,157.3,153.8,127.3,127.2,119.9,110.6,83.4,83.3,81.8,79.2,78.4,60.5,58.2$, $58.1,55.2,54.9,54.9,52.0,51.9,46.3,46.0,37.9,29.0,28.0,27.9,25.5,23.5,14.0,13.8$; HRMS (ESI) calcd for $\mathrm{C}_{24} \mathrm{H}_{36} \mathrm{~N}_{2} \mathrm{O}_{5}: 467.2307$, found: 467.2311; $[\alpha]_{\mathrm{D}}^{25}-32.300\left(\mathrm{CHCl}_{3}, c=0.50\right)$.

\subsubsection{General Synthesis for $\mathbf{1 a}-\mathbf{i}$}

Commercially available tripeptide (1 equiv.) and 7a-i (1 equiv.) was dissolved in $\mathrm{CH}_{2} \mathrm{Cl}_{2} / \mathrm{TFA}$ $(1: 1, v / v)$. After stirred for $2 \mathrm{~h}$ at room temperature, the solvent was removed in vacuum, followed by azeotroping with $\mathrm{CH}_{2} \mathrm{Cl}_{2}$ three times. Then the mixture was dissolved in dry $\mathrm{CH}_{2} \mathrm{Cl}_{2}$. DIPEA was added until reaction mixture was basic, followed by HATU (1.5 equiv.). After stirring for $12 \mathrm{~h}$ at room temperature, the reaction mixture was diluted with EtOAc, washed with $1 \mathrm{M} \mathrm{HCl}$, saturated $\mathrm{NaHCO}_{3}$ solution, water and brine, dried, filtered, and concentrated in vacuum. Purification by silica gel column chromatography $\left(\mathrm{CH}_{2} \mathrm{Cl}_{2} / \mathrm{MeOH}, 20 / 1\right)$ afforded the title compounds $1 \mathbf{a}-\mathbf{i}$.

(S)-2-((R)-2-(Dimethylamino)-3-methylbutanamido)- $N-((3 R, 4 S, 5 S)-3-m e t h o x y-1-((S)-2-((1 R, 2 R)-1-$ meth oxy-2-methyl-3-oxo-3-(3-phenylazetidin-1-yl)propyl)pyrrolidin-1-yl)-5-methyl-1-oxoheptan-4-yl)-N,3dimethylbutanamide (1a). Colorless oil, yield $45 \%$; ${ }^{1} \mathrm{H}-\mathrm{NMR}\left(400 \mathrm{MHz}, \mathrm{CDCl}_{3}\right) 7.40-7.36(\mathrm{~m}, 2 \mathrm{H})$, $7.31-7.27(\mathrm{~m}, 3 \mathrm{H}), 6.93(\mathrm{~d}, J=9.1 \mathrm{~Hz}, 1 \mathrm{H}),[4.87(\mathrm{t}, J=7.2 \mathrm{~Hz})$ and $4.79(\mathrm{t}, J=7.8 \mathrm{~Hz})$, total $1 \mathrm{H}], 4.66-4.59$ $(\mathrm{m}, 1 \mathrm{H}), 4.54-4.46(\mathrm{~m}, 1 \mathrm{H}), 4.45-4.40(\mathrm{~m}, 1 \mathrm{H}), 4.37-4.32(\mathrm{~m}, 1 \mathrm{H}), 4.28-4.23(\mathrm{~m}, 1 \mathrm{H}), 4.21-3.77(\mathrm{~m}, 11 \mathrm{H})$, [3.43 (s) and $3.41(\mathrm{~s})$, total $3 \mathrm{H}],[3.36(\mathrm{~s})$ and $3.35(\mathrm{~s})$, total $3 \mathrm{H}],[3.34(\mathrm{~s})$ and $3.30(\mathrm{~s})$, total $3 \mathrm{H}], 3.14$ $(\mathrm{d}, J=6.2 \mathrm{~Hz}, 1 \mathrm{H}), 3.03-3.02(\mathrm{~m}, 2 \mathrm{H}), 2.63-0.79(\mathrm{~m}, 36 \mathrm{H}) ;{ }^{13} \mathrm{C}-\mathrm{NMR}\left(150 \mathrm{MHz}, \mathrm{CDCl}_{3}\right)$ 174.4, 147.1, 173.8, 173.7, 173.1, 171.2, 170.2, 169.9, 161.8, 161.7, 160.1, 129.2, 129.1, 129.0, 128.8, 128.4, 128.2, 128.1, $127.9,127.7,124.5,124.4,116.0,115.8,115.7,115.6,115.5,86.4,82.6,82.4,78.3,77.8,76.0,61.9,61.8,60.5$, 60.4, 59.4, 59.2, 59.0, 58.1, 57.9, 57.8, 56.5, 56.4, 56.2, 56.0, 55.8, 53.8, 53.6, 53.4, 53.2, 47.7, 47.5, 46.6, 46.5, $42.6,39.4,38.8,37.7,37.4,35.8,33.2,33.1,32.3,31.8,30.9,28.4,27.8,27.7,27.3,26.2,26.0,25.7,25.0,24.9$, 24.6, 23.6, 23.5, 20.1, 19.8, 19.5, 17.9, 17.8, 15.8, 15.4, 14.8, 14.6, 13.7, 13.5, 10.8, 10.7, 10.3; HRMS (ESI) calcd for $\mathrm{C}_{40} \mathrm{H}_{68} \mathrm{~N}_{5} \mathrm{O}_{6}: 714.5164$, found: 714.5169; $[\alpha]_{\mathrm{D}}^{25}-50.200(\mathrm{MeOH}, c=0.50)$.

(S)-2-((R)-2-(Dimethylamino)-3-methylbutanamido)-N-((3R,4S,5S)-1-((S)-2-((1R,2R)-3-(3-(2-fluorophen yl)azetidin-1-yl)-1-methoxy-2-methyl-3-oxopropyl)pyrrolidin-1-yl)-3-methoxy-5-methyl-1-oxoheptan4-yl)-N,3-dimethylbutanamide (1b). Colorless oil, yield $40 \% ;{ }^{1} \mathrm{H}-\mathrm{NMR}\left(400 \mathrm{MHz}\right.$, acetone- $\left.d_{6}\right) \delta$ 7.45-7.38 (m, 1H), 7.36-7.31 (m 1H), 7.23-7.19 (m, 1H), 7.16-7.11 (m, 1H), 4.80-4.63 (m, 3H), 4.45-4.33 $(\mathrm{m}, 2 \mathrm{H}), 4.15-3.93(\mathrm{~m}, 4 \mathrm{H}), 3.68-3.55(\mathrm{~m}, 2 \mathrm{H}),[3.42(\mathrm{~s})$ and $3.33(\mathrm{~s})$, total $3 \mathrm{H}]$, [3.30 $(\mathrm{s})$ and $3.13(\mathrm{~s})$, total $3 \mathrm{H}], 2.75-2.05(\mathrm{~m}, 10 \mathrm{H}), 1.20-0.79(\mathrm{~m}, 24 \mathrm{H}) ;{ }^{13} \mathrm{C}-\mathrm{NMR}\left(150 \mathrm{MHz}\right.$, acetone- $\left.d_{6}\right) \delta 174.2,174.2,172.4$, $170.1,161.2,159.6,128.5,128.4,128.4,128.0,127.9,127.5,127.4,127.3,125.5,124.0,114.8,114.7,114.6$, 81.4, 81.3, 78.7, 73.9, 60.2, 59.0, 58.9, 56.2, 55.2, 53.8, 52.9, 47.1, 47.0, 41.1, 38.2, 37.2, 36.0, 31.7 30.5, 29.6, 29.1, 27.1, 27.0, 26.6, 25.0, 24.2, 23.4, 18.5, 18.1, 17.6, 17.1, 16.9, 14.8, 13.3; HRMS (ESI) calcd for $\mathrm{C}_{40} \mathrm{H}_{67} \mathrm{FN}_{5} \mathrm{O}_{6}: 732.5070$, found: 732.5088; $[\alpha]_{\mathrm{D}}^{25}-35.800\left(\mathrm{CHCl}_{3}, c=0.50\right)$.

(S)-2-((R)-2-(Dimethylamino)-3-methylbutanamido)- $N-((3 R, 4 S, 5 S)-1-((S)-2-((1 R, 2 R)-3-(3-(3-$ fluorophen yl)azetidin-1-yl)-1-methoxy-2-methyl-3-oxopropyl)pyrrolidin-1-yl)-3-methoxy-5-methyl-1-oxoheptan4-yl)-N,3-dimethylbutanamide (1c). Colorless oil, yield 54\%; ${ }^{1} \mathrm{H}-\mathrm{NMR}\left(400 \mathrm{MHz}, \mathrm{CDCl}_{3}\right)$ \& 7.29-7.23 (m, 2H), 7.19-7.11 (m, 1H), 7.06-6.97 (m, 1H), 4.85-4.74 (m, 1H), 4.60-4.54 (m, 1H), 4.52-4.73 (m, 1H), 4.41-4.34 (m, 1H), 4.23-4.17 (m, 2H), 4.12-3.85 (m, 5H), 3.48-3.45 (m, 2H), [3.41 (s) and $3.40(\mathrm{~s})$, total $3 \mathrm{H}$ ], [3.31 (s) and $3.29(\mathrm{~s})$, total $3 \mathrm{H}], 3.05(\mathrm{~s}, 3 \mathrm{H}), 2.64-2.38(\mathrm{~m}, 4 \mathrm{H}), 2.37-2.27(\mathrm{~m}, 6 \mathrm{H}), 2.18-1.77$ $(\mathrm{m}, 10 \mathrm{H}), 1.37-0.76(\mathrm{~m}, 21 \mathrm{H}) ;{ }^{13} \mathrm{C}-\mathrm{NMR}\left(150 \mathrm{MHz}, \mathrm{CDCl}_{3}\right) \delta 174.1,174.0,172.4,170.6,169.9,169.6$, 161.2, 159.6, 159.4, 128.7, 128.3, 128.3, 127.8, 127.2, 127.1, 126.9, 124.1, 123.8, 115.0, 114.9, 114.8, 114.7, 81.3, 79.0, 75.4, 68.9, 60.6, 59.0, 58.9, 58.4, 57.5, 56.8, 56.8, 56.0, 55.6, 53.1, 52.7, 52.6, 47.2, 42.0, 42.0, 38.5, $38.3,36.2,32.0,31.1,30.8,30.2,29.0,28.6,27.3,26.9,25.0,24.3,24.2,23.8,23.7,19.4,19.3,19.1,18.7,17.6$, 17.0, 15.1, 13.7, 13.6; HRMS (ESI) calcd for $\mathrm{C}_{40} \mathrm{H}_{67} \mathrm{FN}_{5} \mathrm{O}_{6}$ : 732.5070, found: 732.5078 ; $[\alpha]_{\mathrm{D}}^{25}-35.200$ $(\mathrm{MeOH}, c=0.50)$. 
(S)-2-((R)-2-(Dimethylamino)-3-methylbutanamido)- $N-((3 R, 4 S, 5 S)-1-((S)-2-((1 R, 2 R)-3-(3-(2-i s o p r o p y l$ phenyl)azetidin-1-yl)-1-methoxy-2-methyl-3-oxopropyl)pyrrolidin-1-yl)-3-methoxy-5-methyl-1-oxohe ptan-4-yl)-N,3-dimethylbutanamide (1d). Colorless oil, yield $48 \% ;{ }^{1} \mathrm{H}-\mathrm{NMR}\left(400 \mathrm{MHz}, \mathrm{CDCl}_{3}\right) \delta$ 7.45-7.40 (m, 1H), 7.33-7.28 (m, 2H), 7.26-7.17 (m, 1H), 5.11-4.69 (m, 3H), 4.35-4.22 (m, 4H), 4.06-4.02 $(\mathrm{m}, 3 \mathrm{H}), 3.57-3.55(\mathrm{~m}, 2 \mathrm{H}),[3.40(\mathrm{~s})$ and $3.38(\mathrm{~s})$, total $3 \mathrm{H}), 3.39-3.01(\mathrm{~m}, 10 \mathrm{H}), 2.66-2.45(\mathrm{~m}, 8 \mathrm{H})$, 2.20-1.95 (m, 6H), 1.88-1.71 (m, 4H), 1.41-1.35 (m, 2H), 1.21-1.13 (m, 8H), 1.02-0.76 (m, 19H); 13C-NMR (150 MHz, CDCl3) $\delta 173.9,173.6,173.1,173.0,172.4,169.7,169.6,169.0,167.6,167.5,159.9,159.7,148.0$, $145.9,145.8,139.2,137.3,134.3,127.3,126.5,126.4,126.4,125.5,125.5,124.8,124.7,124.6,124.6,124.5$, 124.5, 118.8, 117.5, 115.5, 81.56 81.4, 72.6, 72.5, 60.3, 59.8, 59.0, 58.9, 58.3, 56.7, 56.6, 56.3, 56.3, 55.9, 54.0, 53.7, 53.6, 53.4, 46.9, 45.4, 45.3, 40.4, 40.4, 38.3, 38.2, 38.0, 31.8, 29.8, 29.7, 29.0, 28.9, 28.8, 26.8, 26.8, 25.4, 25.3, 25.0, 24.1, 24.0, 23.8, 23.7, 22.8, 22.6, 18.5, 18.4, 18.1, 17.6, 17.5, 17.3, 17.3, 14.8, 13.5, 13.0, 12.7, 9.4; HRMS (ESI) calcd for C43H74N5O6: 778.5453, found: 778.5453; $[\alpha]_{\mathrm{D}}^{25}-40.200\left(\mathrm{CHCl}_{3}, c=1\right)$.

(S)-N-((3R,4S,5S)-1-((S)-2-((1R,2R)-3-(3-(4-Chlorophenyl)azetidin-1-yl)-1-methoxy-2-methyl-3-oxoprop yl)pyrrolidin-1-yl)-3-methoxy-5-methyl-1-oxoheptan-4-yl)-2-((R)-2-(dimethylamino)-3-methylbutanam ido)- $\mathrm{N}, 3$-dimethylbutanamide (1e). Colorless oil, yield $66 \% ;{ }^{1} \mathrm{H}-\mathrm{NMR}\left(400 \mathrm{MHz}, \mathrm{CDCl}_{3}\right) \delta$ 7.44-7.37 $(\mathrm{m}, 4 \mathrm{H}), 4.83-4.67(\mathrm{~m}, 3 \mathrm{H}), 4.40-4.13(\mathrm{~m}, 4 \mathrm{H}), 4.02-3.83(\mathrm{~m}, 4 \mathrm{H}), 3.60-3.55(\mathrm{~m}, 3 \mathrm{H}),[3.40(\mathrm{~s})$ and 3.37 $(\mathrm{s})$, total $3 \mathrm{H}$ ], [3.31 (s) and $3.26(\mathrm{~s})$, total $3 \mathrm{H}], 3.22-3.09(\mathrm{~m}, 4 \mathrm{H}), 2.68-2.39(\mathrm{~m}, 5 \mathrm{H}), 2.28(\mathrm{~s}, 3 \mathrm{H}), 2.27$ (s, 3H), 2.14-1.80 (m, 10H), 1.20-1.13 (m, 4H), 1.02-0.79 (m, 21H); ${ }^{13} \mathrm{C}-\mathrm{NMR}\left(150 \mathrm{MHz}, \mathrm{CDCl}_{3}\right) \delta 173.2$, 172.9, 172.7, 169.7, 169.6, 168.8, 168.7, 141.1, 140.8, 140.6, 140.5, 131.5, 131.4, 128.1, 128.0, 127.9, 127.8, 85.7, 85.5, 81.8, 77.8, 77.6, 77.2, 74.3, 74.2, 60.3, 59.1, 58.6, 58.5, 58.2, 58.1, 56.6, 56.5, 54.2, 54.1, 54.0, 53.9, 53.2, 53.1, 46.5, 46.3, 45.6, 41.0, 38.5, 38.0, 37.9, 36.8, 36.5, 35.2, 31.9, 31.7, 29.9, 28.7, 28.6, 28.5, 28.3, 28.2, $28.1,27.9,26.6,25.5,25.4,25.0,24.9,24.4,24.0,23.7,22.8,18.7,18.5,18.2,17.8$ 17.4, 17.3, 14.8, 14.5, 13.6, 13.5, 12.4, 11.9, 9.5, 9.2; HRMS (ESI) calcd for $\mathrm{C}_{40} \mathrm{H}_{67} \mathrm{ClN}_{5} \mathrm{O}_{6}$ : 748.4774, found: 748.4778 ; $[\alpha]_{\mathrm{D}}^{25}-34.500$ $\left(\mathrm{CHCl}_{3}, c=0.50\right)$.

(S)-N-((3R,4S,5S)-1-((S)-2-((1R,2R)-3-(3-(4-(tert-Butyl)phenyl)azetidin-1-yl)-1-methoxy-2-methyl-3-oxo propyl)pyrrolidin-1-yl)-3-methoxy-5-methyl-1-oxoheptan-4-yl)-2-((R)-2-(dimethylamino)-3-methylbut anamido)-N,3-dimethylbutanamide (1f). Colorless oil, yield $35 \% ;{ }^{1} \mathrm{H}-\mathrm{NMR}\left(400 \mathrm{MHz}, \mathrm{CDCl}_{3}\right) \delta$ 7.44-7.35 (m, 2H), 7.26-7.15 (m, 2H), 4.86-4.69 (m, 3H), 4.64-4.51 (m, 2H), 4.22-4.01 (m, 2H), 4.01-3.76 $(\mathrm{m}, 4 \mathrm{H}), 3.75-3.66(\mathrm{~m}, 4 \mathrm{H}), 3.55-3.47(\mathrm{~m}, 5 \mathrm{H})$, [3.42 $(\mathrm{s})$ and $3.39(\mathrm{~s})$, total $3 \mathrm{H}]$, [3.29 $(\mathrm{s})$ and $3.28(\mathrm{~s})$, total $3 \mathrm{H}], 3.24-3.11(\mathrm{~m}, 3 \mathrm{H}), 3.03-2.62(\mathrm{~m}, 1 \mathrm{H}), 2.59-2.27(\mathrm{~m}, 4 \mathrm{H}), 2.21-1.69(\mathrm{~m}, 3 \mathrm{H}), 1.47-1.15(\mathrm{~m}, 10 \mathrm{H})$, $1.05-0.71(\mathrm{~m}, 18 \mathrm{H}) ;{ }^{13} \mathrm{C}-\mathrm{NMR}\left(150 \mathrm{MHz}, \mathrm{CDCl}_{3}\right) \delta 174.0,173.9,172.5,170.1,170.0,149.8,149.7,137.5$, 137.2, 125.6, 125.1, 81.2, 81.0, 78.8, 60.7, 59.2, 59.0, 57.5, 57.2, 56.8, 54.8, 54.6, 47.6, 47.4, 42.8, 41.9, 41.8, $38.5,38.4,33.8,31.9,31.5,31.3,30.6,30.2,28.6,26.9,25.1,24.3,24.2,23.8,19.2,19.0,18.4,18.4,17.8$, 17.0, 16.6, 15.1, 14.0, 13.8, 12.0, 10.0; HRMS (ESI) calcd for $\mathrm{C}_{44} \mathrm{H}_{76} \mathrm{~N}_{5} \mathrm{O}_{6}$ : 770.5790, found: 770.5809; $[\alpha]_{\mathrm{D}}^{25}-36.000\left(\mathrm{CHCl}_{3}, c=0.50\right)$.

(S)-N-((3R,4S,5S)-1-((S)-2-((1R,2R)-3-(3-([1,1'-Biphenyl]-4-yl)azetidin-1-yl)-1-methoxy-2-methyl-3-oxop ropyl)pyrrolidin-1-yl)-3-methoxy-5-methyl-1-oxoheptan-4-yl)-2-((R)-2-(dimethylamino)-3-methylbuta namido)-N,3-dimethylbutanamide (1g). Colorless oil, yield 70\%; ${ }^{1} \mathrm{H}-\mathrm{NMR}\left(400 \mathrm{MHz}, \mathrm{CDCl}_{3}\right) \delta 7.60$ $(\mathrm{d}, \mathrm{J}=8.4 \mathrm{~Hz}, 4 \mathrm{H}), 7.47-7.44(\mathrm{~m}, 2 \mathrm{H}), 7.40-7.34(\mathrm{~m}, 3 \mathrm{H}), 4.89-4.79(\mathrm{~m}, 3 \mathrm{H}), 4.68-4.65(\mathrm{~m}, 1 \mathrm{H}), 4.58-4.47$ $(\mathrm{m}, 1 \mathrm{H}), 4.45-4.39(\mathrm{~m}, 1 \mathrm{H}), 4.23-3.85(\mathrm{~m}, 10 \mathrm{H})$, [3.45 $(\mathrm{s})$ and $3.42(\mathrm{~s})$, total $3 \mathrm{H}]$, [3.37 $(\mathrm{s})$ and $3.32(\mathrm{~s})$, total 3H], 3.16-3.03 (m, 4H), 2.80-2.02 (m, 10H), 1.26-0.82 (m, 23H); ${ }^{13} \mathrm{C}-\mathrm{NMR}\left(150 \mathrm{MHz}, \mathrm{CDCl}_{3}\right) \delta$ 173.8, 173.5, 169.6, 169.2, 139.8, 139.5, 128.1, 127.0, 126.9, 126.7, 126.5, 126.4, 126.3, 126.2, 81.9, 75.7,58.5, 58.4, 57.3, 57.2, 57.0, 56.9, 54.4, 53.1, 42.1, 38.2, 32.6, 32.5, 32.4, 32.2, 32.1, 31.2, 30.3, 29.0, 28.7, 27.0, 25.7, 25.1, 24.5, 24.4, 24.1, 23.0, 22.0, 19.4, 19.2, 18.9, 17.1, 15.2, 14.1, 13.4, 13.0, 10.1, 9.7; HRMS (ESI) calcd for $\mathrm{C}_{46} \mathrm{H}_{72} \mathrm{~N}_{5} \mathrm{O}_{6}: 790.5477$, found: 790.5475; $[\alpha]_{\mathrm{D}}^{25}-20.900\left(\mathrm{CHCl}_{3}, c=1\right)$.

(S)-N-((3R,4S,5S)-1-((S)-2-((1R,2R)-3-(3-(3-Chloro-4-fluorophenyl)azetidin-1-yl)-1-methoxy-2-methyl-3oxopropyl)pyrrolidin-1-yl)-3-methoxy-5-methyl-1-oxoheptan-4-yl)-2-((R)-2-(dimethylamino)-3-methyl butanamido)-N,3-dimethylbutanamide (1h). Colorless oil, yield $44 \% ;{ }^{1} \mathrm{H}-\mathrm{NMR}\left(400 \mathrm{MHz}, \mathrm{CDCl}_{3}\right) \delta$ 
7.37-7.35 (m, 1H), 7.16-7.09 (m, 2H), 4.90-4.77 (m, 2H), 4.64-4.60 (m, 1H), 4.52-4.40 (m, 2H), 4.18-4.00 $(\mathrm{m}, 4 \mathrm{H}), 3.80-3.76(\mathrm{~m}, 3 \mathrm{H}),[3.43(\mathrm{~s})$ and $3.41(\mathrm{~s})$, total $3 \mathrm{H}]$, [3.38 $(\mathrm{s})$ and $3.36(\mathrm{~s})$, total $3 \mathrm{H}], 3.34-3.30$ $(\mathrm{m}, 4 \mathrm{H}), 3.18-3.02(\mathrm{~m}, 4 \mathrm{H}), 2.37-2.00(\mathrm{~m}, 7 \mathrm{H}), 1.94-1.70(\mathrm{~m}, 10 \mathrm{H}), 1.42-0.80(\mathrm{~m}, 13 \mathrm{H}) ;{ }^{13} \mathrm{C}-\mathrm{NMR}$ $\left(150 \mathrm{MHz}, \mathrm{CDCl}_{3}\right) \delta$ 174.1, 174.0, 172.4, 170.6, 169.6, 161.2, 161.0, 159.6, 159.4, 128.3, 127.8, 127.1, 124.1, $123.8,115.0,114.9,114.8,114.7,81.3,79.0,68.9,60.6,59.0,58.9,58.4,57.5,56.8,56.0,55.6,53.1,52.7,52.6$, 47.2, 42.0, 42.0, 38.5, 38.3, 36.2, 32.0, 31.1, 30.8, 30.2, 29.0, 28.6, 27.3, 26.9, 25.0, 24.3, 24.2, 23.8, 23.7, 19.4, 19.3 19.1, 18.7, 17.6, 17.0, 15.1, 13.7, 13.6, 10.0; HRMS (ESI) calcd for $\mathrm{C}_{40} \mathrm{H}_{66} \mathrm{ClFN}_{5} \mathrm{O}_{6}$ : 766.4680, found: $766.4685 ;[\alpha]_{\mathrm{D}}^{25}-41.400(\mathrm{MeOH}, c=0.50)$.

$(S)-N-((3 R, 4 S, 5 S)-1-((S)-2-((1 R, 2 R)-3-(3-(4-C h l o r o-2-m e t h o x y p h e n y l) a z e t i d i n-1-y l)-1-m e t h o x y-2-$ methyl-3-oxopropyl)pyrrolidin-1-yl)-3-methoxy-5-methyl-1-oxoheptan-4-yl)-2-((R)-2-(dimethylamino) -3-methylbutanamido)- $N, 3$-dimethylbutanamide (1i). Colorless oil, yield 45\%; ${ }^{1} \mathrm{H}-\mathrm{NMR}(400 \mathrm{MHz}$, $\left.\mathrm{CDCl}_{3}\right)$ \& 7.15-7.10 (m, 1H), 7.01-6.92 (m, 1H), 6.87-6.84 (m, 1H), 4.88-4.73 (m, 3H), 4.56-4.50 (m, 1H), 4.45-4.41 (m, 1H), 4.37-4.06 (m, 4H), 3.99-3.91 (m, 2H), [3.83 (s) and $3.80(\mathrm{~s})$, total $3 \mathrm{H}],[3.44(\mathrm{~s})$ and 3.42 (s), total 3H], 3.39-3.29 (m, 5H), 3.14-3.01 (m, 4H), 2.82-2.76 (m, 1H), 2.63-2.24 (m, 7H), $2.31(\mathrm{~s}, 3 \mathrm{H})$, $2.29(\mathrm{~s}, 3 \mathrm{H}), 2.18-1.77(\mathrm{~m}, 9 \mathrm{H}), 1.37-1.13(\mathrm{~m}, 10 \mathrm{H}), 1.05-0.79(\mathrm{~m}, 9 \mathrm{H}) ;{ }^{13} \mathrm{C}-\mathrm{NMR}\left(150 \mathrm{MHz}, \mathrm{CDCl}_{3}\right)$ S 174.4, 173.7, 173.5, 173.2, 171.2, 170.2, 157.9, 133.9, 133.6, 127.9, 127.5, 127.0, 120.6, 111.3, 86.2, 78.5, 78.0, 61.8, 59.4, 58.1, 57.8, 55.8, 53.8, 52.9, 52.6, 47.8, 46.6, 42.7, 39.3, 38.8, 37.4, 35.8, 32.9, 31.9, 28.8, 28.5, 26.0, 25.7, 24.9, 24.4, 23.6, 19.8, 19.4, 18.0, 17.8, 15.8, 13.9, 10.9; HRMS (ESI) calcd for $\mathrm{C}_{41} \mathrm{H}_{69} \mathrm{ClN}_{5} \mathrm{O}_{7}$ : 778.4880, found: $778.4879 ;[\alpha]_{\mathrm{D}}^{25}-33.400(\mathrm{MeOH}, c=0.50)$.

\subsection{Biological Evaluation Methodology}

\subsubsection{Cancer Cell Proliferation Inhibition Assay}

The following cell lines were used for the screening stage, obtained from American Type Culture Collection (ATCC, Manassas, VA, USA); HCT116 human colon cancer cells and A549 human lung carcinoma cell lines were cultured in RPMI 1640 medium supplemented with 10\% FBS. Cell cultures were maintained in a humidified atmosphere of $5 \% \mathrm{CO}_{2}$ at $37^{\circ} \mathrm{C}$. Cells were seeded at 2000 cells per well in 96-well plates in a volume of $200 \mu \mathrm{L}$ per well. The test compounds were dissolved in DMSO and diluted with culture medium to different concentrations. After seeding for $24 \mathrm{~h}$, the medium was removed, and $500 \mu \mathrm{L}$ of the test compound solution was added in duplicates and incubation continued for $72 \mathrm{~h}$ at $37^{\circ} \mathrm{C}$ in a humidified atmosphere containing $5 \% \mathrm{CO}_{2}$. Control cells were treated with vehicle alone. During the last $4 \mathrm{~h}$ of incubation, the cells were exposed to tetrazolium dye (MTT) solution $(5 \mathrm{mg} / \mathrm{mL}, 20 \mathrm{~mL}$ per well). The generated formazan crystals were dissolved in $100 \mathrm{~mL}$ of dimethyl sulfoxide (DMSO), and the absorbance was read spectrophotometrically at $570 \mathrm{~nm}$ using an enzyme-linked immunosorbent assay plate reader. The data was calculated using Graph Pad Prism version 5.0 (GraphPad Softwrae, La Jolla, CA, USA). The $\mathrm{IC}_{50}$ s were fitted using a non-linear regression model with a sigmoidal dose response.

\subsubsection{In Vivo Efficacy Study}

Pathogen-free, 4-6 week-old, female BALB/c athymic mice (Shanghai SCXK Laboratory Animal Technology Co. Ltd., Shanghai, China) were housed under sterile conditions. Human A549 xenograft was established in the right flanks of athymic mice according to the protocol of the National Cancer Institute. When the tumor reached a volume of $100 \mathrm{~mm}^{3}$, the mice were randomly assigned into control ( $n=6$ per group) and treatment groups ( $n=6$ per group). Control group were given lactate buffer, and treatment groups were iv administered with tested compounds. The size of tumor was measured individually on the indicated days. Tumor volume (V) was calculated as $V=\left(\right.$ length $\times$ width $\left.^{2}\right) / 2$. The individual relative tumor volume (RTV) was calculated as follows: $R T V=V_{\mathrm{t}} / V_{0}$, where $V_{\mathrm{t}}$ represented the last tumor size measurement and $V_{0}$ represented the pre-dosing tumor size measurement. The animal experimental protocols were approved by the 
Animal Ethics Committee of School of Pharmacy, Fudan University and the mice were treated in accordance with international animal ethics guidelines.

\section{Conclusions}

In summary, we described the design and synthesis of nine TZT-1027 analogues based on the conformation restriction strategy. 3-Aryl-zetidines were used to replace the phenylethyl group at C-terminus. Two human cancer cell lines (A549, HCT116) were used to evaluate the potency of the synthesized compounds. Compound 1a showed the strongest cytotoxic activities against A549 and HCT 116 cell lines ( $\mathrm{IC}_{50}$ values were $2.2 \mathrm{nM}$ and $2.1 \mathrm{nM}$, respectively). Compound $1 \mathrm{a}$ could not achieve effective inhibition in A549 xenograft models at different dose levels. The poor solubility of 1a limited a further exploration of in vivo activity at higher dosage. Our objective was to discover potent antitumor agents with novel scaffold. In this study, compound 1a did not show any severe toxicity up to $5 \mathrm{mg} / \mathrm{kg}$, showing a better safety potential than TZT-1027 (a dose of $4 \mathrm{mg} / \mathrm{kg}$ seemed to be toxic as reported).

Supplementary Materials: The following are available online at www.mdpi.com/1660-3397/14/5/85/s1, Table S1: Tumor Volume, Table S2: Relative Tumor Volume, Table S3: Tumor Growth Inhibition, Table S4: Solubility of $\mathbf{1 a}$.

Acknowledgments: This work was financially supported by the National High-tech R \& D Program of China (Grant No. 2013AA092903), the National Natural Science Foundation of China (Grant No. 81573340), and "Zhuo Xue" Talent Plan of Fudan University.

Author Contributions: Wei Zhang and Yingxia Li participated in the design of the research and Qi Yan wrote the manuscript. Qi Yan and Yujie Wang performed some of the experimental studies and analyzed the data. All authors read and approved the final manuscript.

Conflicts of Interest: The authors declare no conflict of interest.

\section{Abbreviations}

The following abbreviations are used in this manuscript:

$\begin{array}{ll}\text { Dap } & \begin{array}{l}\text { Dolaproine } \\ \text { Boc }\end{array} \\ \text { HATU } & \text { 2-(7-Azaloxy carbonyl } \\ & \text { hexafluorophosphate } \\ \text { DIPEA } & N, N \text {-Diisopropylethylamine } \\ \text { MTT } & 3-(4,5 \text {-Dimethylthiazol-2-yl)-2,5-diphenyltetrazolium bromide }\end{array}$

\section{References}

1. Pettit, G.R.; Kamano, Y.; Herald, C.L.; Tuinman, A.A.; Boettner, F.E.; Kizu, H.; Schmidt, J.M.; Baczynskyj, L.; Tomer, K.B.; Bontems, R.J. The isolation and structure of a remarkable marine animal antineoplastic constituent: Dolastatin 10. J. Am. Chem. Soc. 1987, 109, 6883-6885. [CrossRef]

2. Watanabe, J.; Minami, M.; Kobayashi, M. Antitumor activity of TZT-1027 (soblidotin). Anticancer Res. 2006, 26, 1973-1981. [PubMed]

3. Bai, R.; Petit, G.R.; Hamel, E. Dolastatin 10, a powerful cytostatic peptide derived from a marine animal: Inhibition of tubulin polymerization mediated through the vinca alkaloid binding domain. Biochem. Pharmacol. 1990, 39, 1941-1949. [CrossRef]

4. Maderna, A.; Leverett, C.A. Recent advances in the development of new auristatins: Structural modifications and application in antibody drug conjugates. Mol. Pharm. 2015, 12, 1798-1812. [CrossRef] [PubMed]

5. Pettit, G.R.; Singh, S.B.; Hogan, F.; Lloyd-Williams, P.; Herald, D.L.; Burkett, D.D.; Clewlow, P.J. Antineoplastic agents. Part 189. The absolute configuration and synthesis of natural (-)-dolastatin 10. J. Am. Chem. Soc. 1989, 111, 5463-5465. [CrossRef] 
6. Miyazaki, K.; Kobayashi, M.; Natsume, T.; Gondo, M.; Mikami, T.; Sakakibara, K.; Tsukagoshi, S. Synthesis and antitumor activity of novel dolastatin 10 analogs. Chem. Pharm. Bull. 1995, 43, 1706-1718. [CrossRef] [PubMed]

7. Yamamoto, N.; Andoh, M.; Kawahara, M.; Fukuoka, M.; Niitani, H. Phase I study of TZT-1027, a novel synthetic dolastatin 10 derivative and inhibitor of tubulin polymerization, given weekly to advanced solid tumor patients for 3 weeks. Cancer Sci. 2009, 100, 316-321. [CrossRef] [PubMed]

8. Horti, J.; Juhasz, E.; Monostori, Z.; Maeda, K.; Eckhardt, S.; Bodrogi, I. Phase I study of TZT-1027, a novel synthetic dolastatin 10 derivative, for the treatment of patients with non-small cell lung cancer. Cancer Chemother. Pharmacol. 2008, 62, 173-180. [CrossRef] [PubMed]

9. Senter, P.D.; Sievers, E.L. The discovery and development of brentuximab vedotin for use in relapsed hodgkin lymphoma and systemic anaplastic large cell lymphoma. Nat. Biotechnol. 2012, 30, 631-637. [CrossRef] [PubMed]

10. Maderna, A.; Matthew, D.; Chakrapani, S.; Alexander, P.; Leverett, C.A.; Vetelino, B.C.; Zecheng, C.; Hud, R.; Kevin, P.; Jayvardhan, P. Discovery of cytotoxic dolastatin 10 analogues with N-terminal modifications. J. Med. Chem. 2014, 57, 10527-10543. [CrossRef] [PubMed]

11. Cormier, A.; Marchand, M.; Ravelli, R.B.G.; Knossow, M.; Gigant, B. Structural insight into the inhibition of tubulin by vinca domain peptide ligands. EMBO Rep. 2008, 9, 1101-1106. [CrossRef] [PubMed]

12. Evans, G.B.; Furneaux, R.H.; Greatrex, B.; Murkin, A.S.; Schramm, V.L.; Tyler, P.C. Azetidine based transition state analogue inhibitors of $\mathrm{N}$-ribosyl hydrolases and phosphorylases. J. Med. Chem. 2008, 51, 948-956. [CrossRef] [PubMed]

13. Allwood, D.M.; Blakemore, D.C.; Brown, A.D.; Ley, S.V. Metal-free coupling of saturated heterocyclic sulfonylhydrazones with boronic acids. J. Org. Chem. 2014, 79, 328-338.

14. Kobayashi, M.; Natsume, T.; Tamaoki, S.; Watanabe, J.-I.; Asano, H.; Mikami, T.; Miyasaka, K.; Miyazaki, K.; Gondo, M.; Sakakibara, K.; et al. Antitumor activity of TZT-1027, a novel doiastatin 10 derivative. Jpn. J. Cancer Res. 1997, 88, 316-327.

15. Watanabe, J.; Natsume, T.; Kobayashi, M. Antivascular effects of TZT-1027 (Soblidotin) on murine colon26 adenocarcinoma. Cancer Sci. 2006, 97, 1410-1416.

(C) 2016 by the authors; licensee MDPI, Basel, Switzerland. This article is an open access article distributed under the terms and conditions of the Creative Commons Attribution (CC-BY) license (http://creativecommons.org/licenses/by/4.0/). 